\title{
Regurgitation of blood flow from the ectatic LAD artery as a cause of angina demonstrated during coronary angiogram
}

\author{
Iranna Hirapur, ${ }^{1}$ Rajeshwari Veeranna, ${ }^{2}$ Navin Agrawal ${ }^{3}$
}

${ }^{1}$ Department of Cardiology, R L Jalappa, Narayana Hrudalaya Heart Center, Kolar, Karnataka, India

${ }^{2}$ Department of Opthalmology, R L Jalappa, Narayana Hrudalaya Heart Center, Kolar, Karnataka, India ${ }^{3}$ Department of Cardiology, Care Hospital, Surat, Gujarat, India

\section{Correspondence to}

Dr Navin Agrawal,

drnavinagrawal@gmail.com, dr_navinagrawal@yahoo.co.in

Accepted 24 January 2014
CrossMark

\section{DESCRIPTION}

We present an interesting fluoroscopic angiographic image of a 55-year-old patient who presented to us with a 1-month history of breathlessness and inexplicable nocturnal angina. The ECG and echocardiography were normal and the treadmill test was positive. Coronary angiogram revealed dilated and ectatic blood vessels with systolic regurgitation of blood from the left anterior descending artery (LAD) into the left circumflex artery (LCX) (figure 1, videos 1-3). There was no other obstructive lesion in the vessels. The nocturnal angina was explained by the coronary ectasia and systolic reflux of blood form the LAD. The corrected thrombolysis in myocardial infarction (TIMI) frame count was slightly above the normal range in LAD and LCX (28 in LAD and 29 in LCX). The patient was put on antiplatelets, statins and nitrates on which her symptoms partially improved.

Papadakis et $a l^{1}$ reported that the TIMI Frame Count was higher in ectatic vessels, and structural alterations including breakdown of the vessel wall could explain the increased susceptibility to thrombosis and vasospasm precipitating angina, which could be worsened by blood reflux possibly caused by the absence of antegrade flow gradient in diastole due to coronary dilation.

Although coronary ectasia is a relatively common finding in contemporary cardiological practice (in $3-8 \%$ of angiographic and $0.22-1.4 \%$ of autopsy series), ${ }^{2}$ ectasia is usually seen in association with

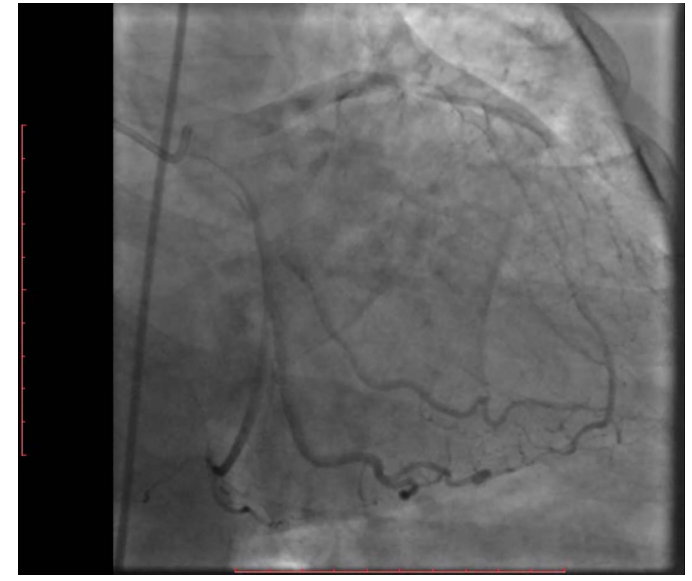

Video 1 RAO caudal view showing ectatic coronary arteries with reflux of dye from the left anterior descending artery to the left circumflex artery

atherosclerosis, unlike this patient, and the pattern of reflux of dye seen from one vessel to another has never been described and is an interesting illustration of a pathophysiological phenomenon which could generally explain the occurrence of angina in such kind of patients. However, other pathophysiological mechanisms of angina-like microcirculatory abnormalities and endothelial dysfunction should also be considered as an important differential diagnosis in all such cases.

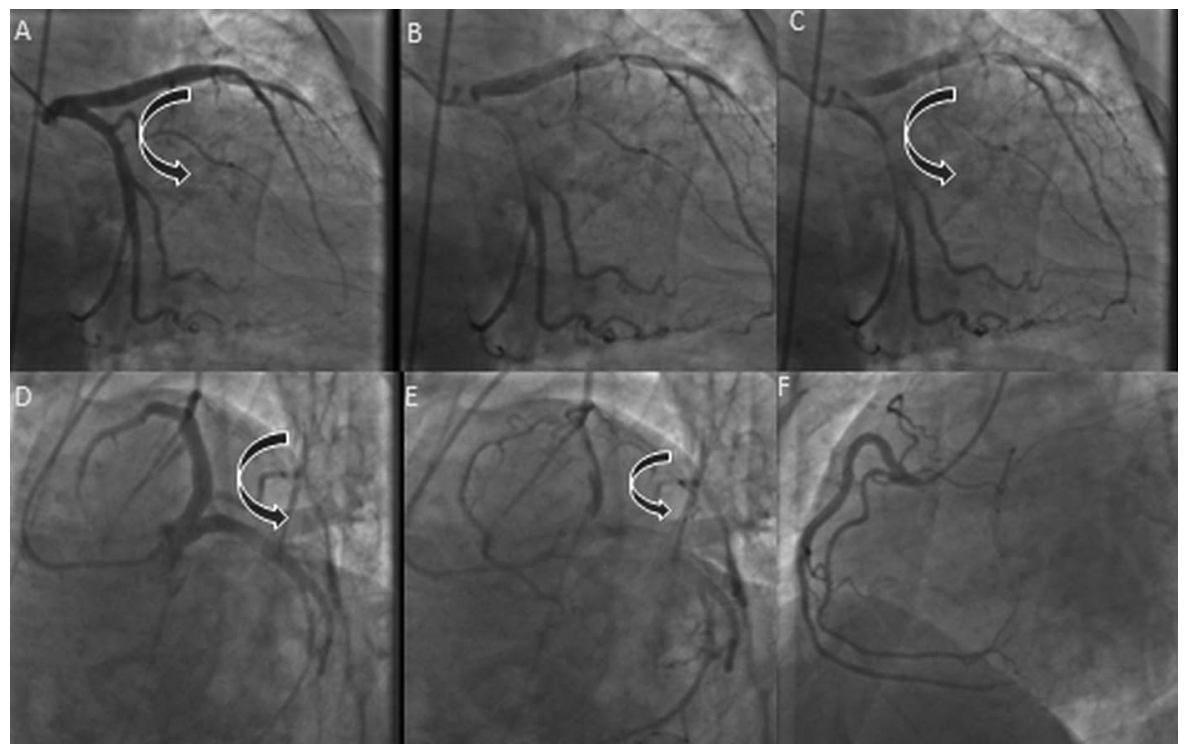

Figure 1 A collage of images showing the pattern of reflux in the coronary arteries seen in consecutive images frames. 


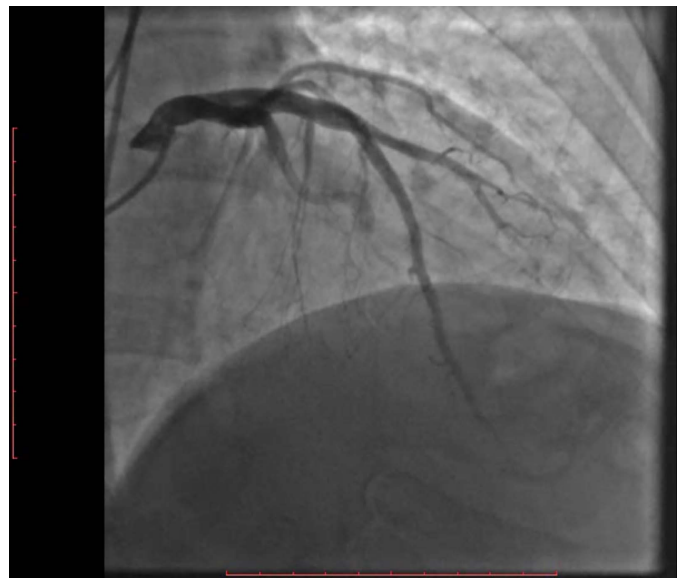

Video 2 LAO cranial view showing dye refluxing from the LAD to the LCX artery

\section{Learning points}

- Coronary ectasia can cause slow flow in coronaries which can explain the association of angina in these patients.

- Absence of antegrade flow gradient due to coronary dilation in systole can lead to reflux of blood from coronaries which can cause underperfusion of vital areas which, in turn, can lead to angina.

- Reflux of dye from coronaries in ectatic vessels has been demonstrated angiographically earlier and can be a pathophysiological explanation for the previously unexplained angina in patients with ectatic vessels.

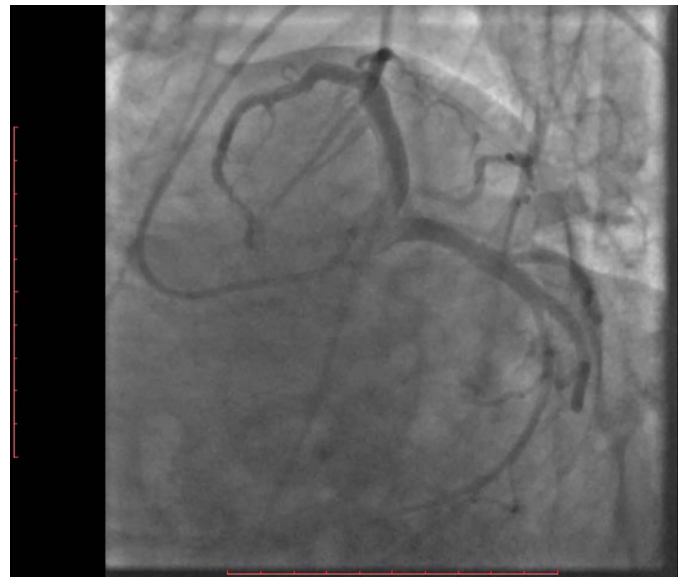

Video 3 LAO caudal view showing dye reflux from LAD to LCX

Contributors $\mathrm{HH}, \mathrm{RV}$ and NA have contributed to the drafting and finalising of the document and have helped in patient care.

Competing interests None.

Patient consent Obtained.

Provenance and peer review Not commissioned; externally peer reviewed.

\section{REFERENCES}

1 Papadakis MC, Manginas A, Cotileas P, et al. Documentation of slow coronary flow by the TIMI frame count in patients with coronary ectasia. Am J Cardiol 2001;88:1030-2.

2 Demopoulos VP, Olympios CD, Fakiolas $C N$, et al. The natural history of aneurysmal coronary artery disease. Heart 1997;78:136-41.

Copyright 2014 BMJ Publishing Group. All rights reserved. For permission to reuse any of this content visit

http://group.bmj.com/group/rights-licensing/permissions.

BMJ Case Report Fellows may re-use this article for personal use and teaching without any further permission.

Become a Fellow of BMJ Case Reports today and you can:

- Submit as many cases as you like

- Enjoy fast sympathetic peer review and rapid publication of accepted articles

- Access all the published articles

- Re-use any of the published material for personal use and teaching without further permission

For information on Institutional Fellowships contact consortiasales@bmjgroup.com

Visit casereports.bmj.com for more articles like this and to become a Fellow 